\title{
La máquina de crecimiento en una ciudad minera y el papel del espacio público: el proyecto Parque Kaukari,
} Copiapó

\author{
A park for the mining town: public space, real estate investment and urban growth machine in Copiapó
}

\author{
Johannes Rehner* y Sebastián Rodríguez**
}

Recibido: 25 de octubre de 2017

Aceptado: 14 de mayo de 2018

\section{Resumen}

El auge exportador en Chile ha transformado las ciudades del norte, generando un rápido crecimiento urbano, cambiando estructuras y promoviendo proyectos emblemáticos, entre ellos espacios públicos como el parque Kaukari en Copiapó. Este responde a una necesidad de la ciudad, debido a la deficiencia de los espacios públicos en cuanto a cantidad y calidad, pero también se puede interpretar como parte de una lógica de crecimiento urbano, intrínsecamente vinculada a la reproducción del capital y a la liquidez financiera. En este sentido, es que el presente trabajo tiene como propósito recuperar la propuesta conceptual de la "máquina de crecimiento", cuestionando su aplicabilidad al caso de ciudades mineras, bajo la influencia de un auge exportador. Lo hace discutiendo el vínculo conceptual entre el impulso generado por el auge minero, la materialización de liquidez en inversión inmobiliaria y la construcción de espacios públicos. Para ilustrar esta reflexión se presenta un análisis exploratorio de la distribución espaciotemporal de los permisos de edificación en Copiapó, y de ciertos elementos del discurso sobre proyectos de espacio público, particularmente el Parque Kaukari. Los resultados permiten reconocer cómo los discursos sobre este parque en particular se articulan con la lógica de crecimiento además de una orientación de los permisos de edificación presentados por empresas hacia las grandes obras de infraestructura. Se puede suponer que esto produce beneficios económicos para ciertos agentes, pero también se construye una nueva centralidad y el proyecto parque promete cumplir con algunas exigencias de la ciudadanía.

Palabras clave: espacio público, inversión inmobiliaria, máquina de crecimiento.

\begin{abstract}
Chile's export boom has transformed northern cities, generating rapid urban growth, changing structures and promoting emblematic projects, including public spaces such as Kaukari Park in Copiapó. This responds to some shortcomings of the city, as the deficiency of public spaces in terms of quantity and quality, but it is also an expression of a logic of urban growth, intrinsically linked to the reproduction of capital and to financial liquidity. In this sense, it is that the present work aims to recover the conceptual proposal of the "growth machine", questioning its applicability to the case of mining cities, under the influence of an export boom. It does so by discussing the conceptual link between the momentum generated by the mining boom, the materialization of liquidity in real estate investment and the construction of public spaces. To illustrate this reflection, an exploratory analysis of the spatialtemporal distribution of building permits in Copiapó, and of certain elements of the discourse on public space projects, particularly Kaukari Park, is presented. The results illustrate how the discourses on this particular park are articulated with a premise of growth and it shows the orientation of building permits submitted by companies and specifically the real estate sector towards large infrastructure projects. It can be assumed that this produces economic benefits for certain agents, but a new centrality is also being built and the park project promises to meet some citizen demands.
\end{abstract}

Keywords: growth machine, public space, real estate.

\footnotetext{
*Pontificia Universidad Católica de Chile, Santiago, Chile. Contacto: jrehner@uc.cl

** Pontificia Universidad Católica de Chile, Santiago, Chile. Contacto: sirodri1@uc.cl

Trabajo financiado por el proyecto Fondecyt 1150636 y el proyecto FONDAP CEDEUS
}

Cómo citar: Rehner, J. y Rodríguez, S. (2018). La máquina de crecimiento en una ciudad minera y el papel del espacio público: el proyecto Parque Kaukari, Copiapó. Revista de Urbanismo, 38, 1-22. http://dx.doi.org/10.5354/0717$\underline{5051.2018 .50434}$ 


\section{Introducción}

Las ciudades del norte chileno se perciben como ciudades con fuerte contradicción interna entre el elevado ingreso generado por la minería y la deficiente calidad urbana, particularmente de sus espacios públicos. El auge exportador no ha transformado solamente los territorios de extracción minera propiamente tal, sino que también ha marcado las ciudades, espacios que se articulan como nodos receptores de ingresos provenientes de la actividad minera (Rehner, Rodriguez \& Murray 2018). Por su parte, el espacio público se considera elemento central de la cualidad urbana, expresión de lo cívico y en consecuencia un elemento clave para un desarrollo urbano sustentable en su visión de ciudad compacta e incluyente (Gehl, 2006; Pozueta, 2009; Rueda, 2007).

Comprender conceptualmente la relación entre la exportación de cobre, las dinámicas inmobiliarias y la construcción de espacio público, reflexionando sobre la aplicabilidad de la "máquina de crecimiento" como principal propuesta conceptual, es el objetivo principal que guía la presente investigación. Particularmente, se propone aclarar la pregunta, qué papel juega la construcción de espacio público en el contexto de una ciudad marcada por la ciclicidad de auge exportador y crisis económica, complementado por una generalizada financiarización de la economía urbana. Esta pregunta se discute empleando el proyecto Parque Kaukari en Copiapó como caso de estudio.

La estructura de trabajo se configura en base a cinco apartados. Primero se plantea una discusión de la relación entre la actividad exportadora y el sector inmobiliario, seguido por una reflexión en torno al concepto de la máquina de crecimiento y su vínculo con el espacio público. Después de un breve apartado que da cuenta de la metodología empleada, se presentan los resultados en el cuarto capítulo, discutiendo e interpretando las características de auge minero, dinámica inmobiliaria y construcción del Parque Kaukari como espacio público. Finalmente se plantean las conclusiones e implicancias del trabajo realizado.

Ciudades en auge: la relación entre la actividad exportadora y el sector inmobiliario

A comienzos del siglo actual, Chile ha experimentado un fuerte aumento de las exportaciones de recursos naturales, razón por la cual el valor de la exportación ha pasado de unos 10.000 millones US\$ a comienzos de los años noventa a más que 63.000 millones US\$ en 2015 . Dicho crecimiento fue impulsado en gran medida por la bonanza que experimentó el precio del cobre a escala mundial (Figura 1). La exportación de este mineral representa el 53\% (2015) del total de las exportaciones chilenas, contribuyó en promedio un $13,32 \%$ al Producto Interno Bruto (2006-2015) (Banco Central de Chile, 2017); recibió un tercio de la inversión extranjera y aportó en promedio $17,5 \%$ al ingreso fiscal (2006-2015) (Minería Chilena, 2016, p. 29-30).

\section{Ciudades en auge: la relación entre la actividad exportadora y el sector inmobiliario}

A comienzos del siglo actual, Chile ha experimentado un fuerte aumento de las exportaciones de recursos naturales, razón por la cual el valor de la exportación ha pasado de unos 10.000 millones US\$ a comienzos de los años noventa a más que 63.000 millones US\$ en 2015. Dicho crecimiento fue impulsado en gran medida por la bonanza que experimentó el precio del cobre a escala mundial (Figura 1). La exportación de este mineral representa el 53\% (2015) del total de las exportaciones chilenas, contribuyó en promedio un $13,32 \%$ al Producto Interno Bruto (2006-2015) (Banco Central de Chile, 2017); recibió un tercio de la inversión extranjera y aportó en promedio $17,5 \%$ al ingreso fiscal (2006-2015) (Minería Chilena, 2016, p. 29-30). 


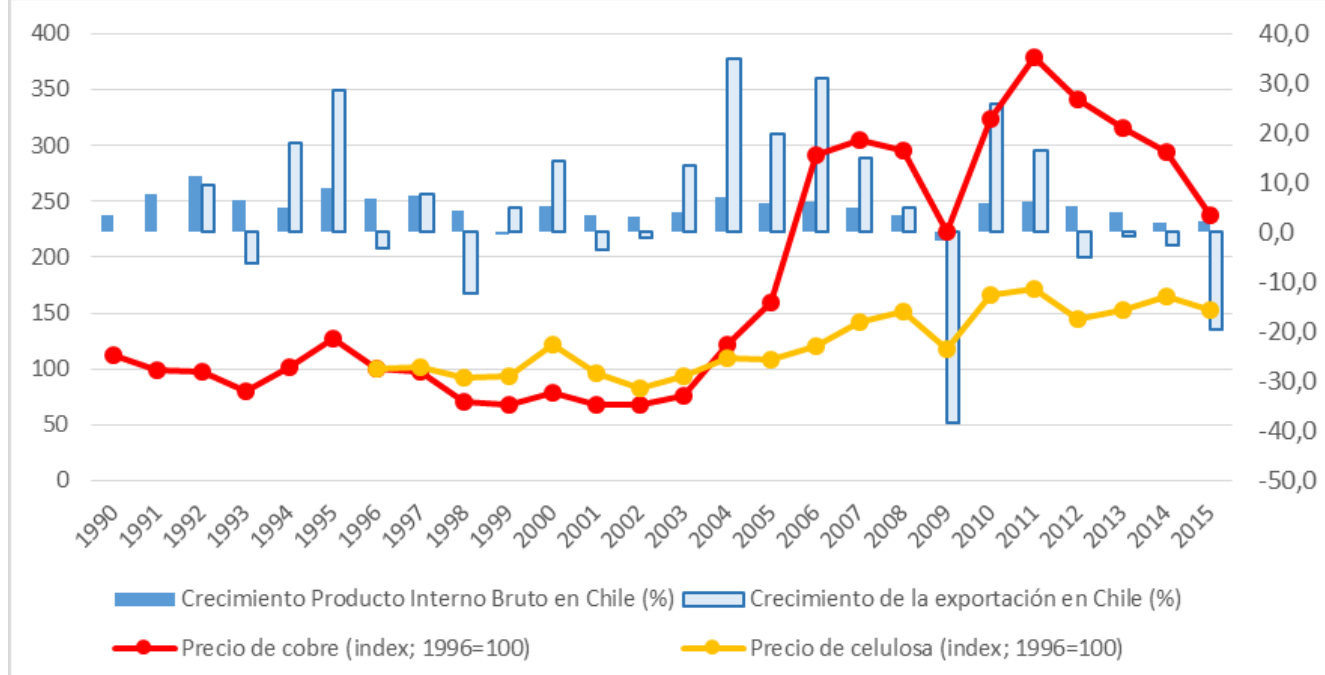

Figura 1: Crecimiento de Exportación, PIB e índices de precios de cobre y celulosa

Fuente: Elaboración propia con base en: Banco Central de Chile, 2016; Servicio Nacional de Aduanas, 2016.

Los últimos 15 años han sido marcados por la presencia de evidentes fases de auge y crisis. A partir de 2003, los precios internacionales de bienes primarios aumentaron de manera considerable y sostenida en el tiempo, siendo el cobre un claro ejemplo de ello, mostrando un mayor dinamismo que otros productos de importancia para Chile, como lo es el precio de la celulosa. Sin embargo, entre 2008 y 2009 y como consecuencia de la crisis "subprime", el precio de algunos productos y el valor de la exportación nacional declinó notoriamente (Daher, 2017), para luego mostrar una fuerte recuperación entre 2011 y 2012. Finalmente, desde 2013 en adelante se observa una caída lenta, pero sostenida (Figura 1).

A pesar de la importancia que poseen las exportaciones de cobre para la economía nacional, su aporte al desarrollo del país más allá de generar ingreso y fomentar el crecimiento, ha sido puesto en duda. Tal cuestionamiento se basa parcialmente en la tesis de la maldición de los recursos. Auty (1993) y Sachs \& Warner (1995) utilizaron este término para referirse al efecto que los países dotados con abundantes recursos naturales, a pesar de un auge exportador, tienden a un menor crecimiento económico que otros países, teniendo resultados negativos como por ejemplo mayor desigualdad del ingreso, estancamiento del desarrollo, corrupción o inestabilidad política (Badeeb, Lean \& Clark,
2016; Muñoz-García, 2011). Uno de los diversos elementos explicativos del por qué se produce la llamada maldición de recursos, se basa en la tesis del síndrome holandés (Corden \& Neary, 1982). Los autores de esta tesis argumentan que, cuando un sector exportador en particular entra en una fase de auge, se producen efectos negativos sobre otros sectores exportadores, como por ejemplo la agricultura o la industria manufacturera. Estos rubros sin auge experimentan una fuga de fuerza laboral y capital o sufren de un efecto adverso del tipo de cambio, dado que la fortaleza de la moneda nacional se traduce en una desventaja en los mercados internacionales, porque encarece los productos exportados y hace la importación más barata. Por ende, estas actividades ajenas al sector en auge reducen su producción. Por otro lado, se esperan efectos positivos sobre bienes o servicios no exportables, como es el caso del comercio y la construcción, quienes pueden experimentar crecimiento en base al gasto de ingresos generados por el sector en auge (Corden, 1984; Sánchez, García de la Cruz \& Mora, 2014; Van Wijnbergen, 1984). El último efecto es particularmente relevante para el presente trabajo, dado que los sectores con posibles beneficios son principalmente urbanos.

Es preciso destacar que tal argumentación económica se basa en la escala nacional, la perspectiva regional y urbana es una rama más reciente de estudio de los impactos de la exportación primaria. Para discutir el 
vínculo entre la renta exportadora y la ciudad se requiere reflexionar sobre cómo los efectos traspasan escalas (Rehner, Rodríguez \& Murray, 2018). Considerando las condiciones geográficas del territorio chileno y el muy marcado perfil productivo de la mayoría de las regiones (Daher, 2003), es que, al traspasar escalas, los impactos del auge exportador difieren según el territorio. Por ejemplo, el elevado precio del cobre en los mercados globales ha impulsado la exportación a nivel nacional, pero ha presentado una marcada volatilidad, favoreciendo la economía de algunas regiones mucho más que otras (Rehner, Baeza \& Barton, 2014). Se ha constatado que el auge minero no ha producido el desarrollo tecnológico y de alto capital humano esperado de los cluster y no ha presentado los esperados impactos positivos sobre la economía local (Atienza, Lufín, Soto \& Cortés, 2015).

Sin embargo, es apreciable que varias ciudades del norte chileno, centros de territorios mineros, han experimentado un vertiginoso crecimiento de sus economías urbanas, reflejado en el incremento significativo del empleo, de las remuneraciones, acompañado por un alto nivel de precios y significativa población inmigrante, entre otros (Rehner, Rodriguez \& Murray, 2018). Tales "ciudades en auge" no solo muestran un crecimiento en sectores ligados a la actividad extractiva-exportadora, sino que también, en sectores productores de bienes y servicios "no exportables", de acuerdo con lo planteado por la tesis de síndrome holandés (Corden \& Neary, 1982). Se puede constatar entonces que un aumento en el precio del cobre produce transformaciones de las economías urbanas en Chile. Este efecto se asocia con un aumento del consumo y de la construcción de inmuebles. Se ha demostrado por ejemplo que en las ciudades de Copiapó y La SerenaCoquimbo, en la fase de auge del cobre, mediante tales efectos indirectos, se crearon puestos de trabajo sobre todo en los rubros construcción y comercio (Rehner \& Vergara, 2014).

Sumado a esto, también las empresas, particularmente el sector financiero y además el Estado, reciben parte de esta renta durante las fases de auge, lo cual aumenta la disponibilidad de capital financiero para ser invertido en las ciudades. Esta abundancia de capital financiero genera una mayor demanda por objetos inmobiliarios, lo cual provoca un aumento en el valor de estos, permitiendo así una alta rentabilidad del capital invertido en el sector inmobiliario. Harvey (2006) interpreta ciudades como la materialización espacial del exceso de capital, dado que este necesita ser invertido y reproducido bajo las leyes propias del capital. Esto va acompañado por una creciente financiarización de la economía urbana en general (Pike \& Pollard, 2010). Sosteniendo este argumento, se ha demostrado en el contexto chileno que la fase de auge exportador y mayor liquidez, se asocia con mayor cantidad de permisos de edificación y por ende mayor disposición de invertir en actividades inmobiliarias (Rehner \& Rodríguez, 2017). Así, es posible interpretar ciudades en auge como producto del círculo conformado por los ingresos obtenidos de la exportación - tanto por las empresas como por los hogares- y de la necesidad de materialización y reproducción del capital financiero.

\section{La "máquina de crecimiento" y el espacio público}

En la década de los 70', en la misma época que David Harvey (1978) discutió el segundo circuito del capital y la materialización del capital en la ciudad, el sociólogo estadounidense Harvey Molotch (1976) introdujo la metáfora de la "máquina de crecimiento" (growth machine), proponiendo una reflexión más bien relacional sobre el capital y la ciudad, enfocada en la agencia. Esta conceptualización analiza las alianzas entre diferentes élites urbanas, que coinciden en la búsqueda de crecimiento y se pregunta cómo la ciudad es el vehículo a través de cual las élites obtienen beneficios directos del crecimiento (Logan \& Molotch, 1987). Evidentemente, en una ciudad de alto crecimiento económico, los agentes inmobiliarios y financieros realizan mayor renta de suelo, a través de un aumento de los precios inmobiliarios, pero también otros rubros económicos se benefician, debido a economías de escala resultantes del crecimiento de su mercado $y$, además, el sector político adquiere mayor poder derivado de la creciente importancia de la ciudad (Molotch, 1976).

La metáfora de la "máquina de crecimiento" se refiere entonces a la formación de una alianza local entre diferentes actores con importantes recursos de poder en la búsqueda de renta de tierra urbana (Smith \& Floyd 2013). En otros temas, estos agentes compiten entre sí, 
pero establecen un consenso en torno a una ideología de crecimiento (Molotch, 1976). Así, se promueve el crecimiento de la ciudad en población, en actividades económicas e implícitamente en extensión de su superficie urbana. Aunque este último punto y el vínculo con la suburbanización no es un tema central de la discusión planteada en la máquina de crecimiento, dado que la renta inmobiliaria se puede realizar tanto por mayor intensidad en el uso de suelo como por el aumento del área urbanizada. El análisis de tal alianza no se refiere solamente a medidas concretas para fomentar la inversión por parte de la política y la movilización de recursos financieros por el sector privado, sino también a la dimensión discursiva, destacando el papel de los medios de comunicación, ya que grandes proyectos requieren justificación pública y legitimación discursiva. A través de discursos públicos se promueve una ideología procrecimiento, una visión a futuro marcado por la imagen de una ciudad con mayor edificación, con vibrante actividad económica, con nueva infraestructura, y más próspera. El anteriormente mencionado argumento neomarxista sobre el segundo circuito del capital y la materialización del excedente en la ciudad para producir nueva renta (Harvey, 1978), requiere de tal "máquina de crecimiento". Sin crecimiento y sobre todo sin un discurso dominante que sostiene la lógica de crecimiento, la inversión en la ciudad no encontraría una demanda ni una expectativa sobre una futura valorización y por ende, los precios no tendrían tendencia al alza y no podrían producir rentabilidad.

Por su postura explícitamente crítica frente a este discurso que iguala crecimiento a prosperidad y desarrollo, el trabajo de Molotch (1978) puede ser entendido como expresión de una postura radical sobre de desarrollo urbano sustentable. Si bien, evidentemente el crecimiento económico no necesariamente significa desarrollo, otros han planteado que tampoco hay una contradicción fundamental entre crecimiento y desarrollo sustentable, siendo considerado el crecimiento económico necesario para le mejora de la calidad de vida, pero un crecimiento principalmente material se vuelve insostenible a largo plazo (Gallopín 2003: 28-30). En este sentido, se ha planteado ya hace décadas que la clave para vincular crecimiento con sustentabilidad es que en conjunto con un mayor crecimiento se logre mejorar la distribución de la riqueza para disminuir la brecha de desigualdad (Guimarães 1994). Desde esta perspectiva, la constatación de una política pro-crecimiento (en el sentido de la "máquina de crecimiento") no significaría necesariamente una contradicción con la meta de un desarrollo sustentable.

El concepto de espacio público cabe en la discusión sobre la máquina de crecimiento en dos sentidos. Por un lado, se puede considerar un elemento que pone límite a una ideología solamente enfocada en el crecimiento, destacando la función de estos espacios en una visión de desarrollo urbano sustentable. Por otro lado, desde una visión netamente económica, los espacios públicos se pueden interpretar como fuente de externalidades positivas para el sector inmobiliario (Smith \& Floyd, 2013). Estudios actuales han discutido esta relación conceptual (Loughran, 2014), destacando la importancia del valor inmobiliario creado por sobre todo a través de parques urbanos, aunque en la bibliografía clásica ya se había señalado que la existencia de espacios públicos no siempre beneficia a los ciudadanos y tampoco necesariamente produce plusvalía inmobiliaria (Jacobs, 1961). En términos más generales, se ha discutido cómo la utilización del imaginario verde en los proyectos inmobiliarios ha contribuido a generar mayor acumulación de capital en los agentes promotores, vinculando los espacios verdes a beneficios asociados a la vida saludable y a la lejanía con áreas urbanas contaminadas (Irarrázaval, 2012; Ríos y Pírez, 2008).

Para la profundización de esta discusión, es pertinente recordar algunas principales dimensiones constituyentes del concepto de espacio público en base a una revisión de la literatura.

1. Funcionalidad y morfología: Esta dimensión se relaciona con algunas características necesarias para el funcionamiento de la urbe, como es el desplazamiento de las personas o la recreación, y por ende es un elemento articulador y estructurante de la ciudad (División de Desarrollo Urbano/Ministerio de Vivienda y Urbanismo de Chile, 2009). Por esta razón los espacios públicos requieren de una morfología predominantemente abierta, que permite el libre acceso de las personas. Un papel destacado en este sentido tienen los centros históricos de las ciudades (Carrión, 2005). Es importante mencionar la crítica referida a una visión técnicoinstrumental del concepto espacio público, que solía predominar en la planificación urbana (León Balza, 1998). 
El diseño de las ciudades y sus espacios públicos en este sentido es un elemento clave no solamente para un correcto funcionamiento logístico, sino por sobre todo, para su característica humana (Gehl, 2006).

2. Posiblemente la característica más destacada de los espacios públicos es su rol como elemento constitutivo de ciudadanía (Borja y Muxi, 2000). Es el lugar "donde se expresan y se forman voluntades colectivas para que la sociedad se represente en sus derechos y deberes" (Carrión, 2005, p. 95). Por ende, hay un vínculo directo entre el valor cívico del espacio público y el concepto de "esfera pública" en el sentido de Habermas (Defilippis, 1997, p. 414). Tal visión, reconoce que la representación democrática de distintas voces requiere de los espacios públicos para expresar las distintas posturas (Mitchell, 2003). A esta perspectiva se suma la visión desde el anarquismo del espacio público como "campo de batalla" entre grupos antagónicos (Springer 2011, p. 526) sin posibilidad de un verdadero encuentro, pero con importancia central para la visibilidad de los grupos.

3. Diversidad, multiplicidad de usos y encuentro social. Autores como Salcedo Hansen (2002) enfatizan el papel integrador a través del encuentro de lo diverso. Desde tal perspectiva el espacio público se considera "un espacio simbiótico en el sentido que genera integración, articulación, encuentro y conectividad de los distintos" (Carrión 2005, p. 95). Esto, se relaciona con el valor cívico, ya que el criterio de la diversidad y encuentro tiene destacada relevancia para el diálogo democrático (Saraví, 2004 , p. 36). Por otro lado, la búsqueda de salubridad y orden a través del control constituye una amenaza para esta dimensión, ya que una marginalización de ciertos grupos del espacio público las hace invisibles (Cook \& Whowell, 2011). El espacio público ha sido considerado un importante elemento de cohesión social (Ministerio de Vivienda y Urbanismo 2017) y se ha afirmado que cuando son de buena calidad pueden reducir la desigualdad y la exclusión en las urbes (ONU Habitat; CAF, 2014). En este sentido el espacio público es visto también como un espacio de contestación y de apropiación incluso cuando tenga característica pseudo-pública (Capulong Reyes, 2016).

4. El espacio público como elemento constituyente de identidad. Autores clásicos del urbanismo (Jacobs, 1958) han destacado el papel formador de identidad de los espacios públicos, especialmente de los espacios urbanos céntricos. La característica compacta e inclusiva del espacio público, produce interacciones múltiples y de este modo da lugar a la formación de identidad local. Esto se ha presentado como una expresión del urbanismo ciudadano en contraste al urbanismo globalizado unificador (Borja, 2007), siendo este último caracterizado por lo difuso, fragmentado, mercantilizado, la lógica de la competitividad y la construcción de proyectos emblemáticos. Vinculado con esta visión se entiende el "mundo de la calle" como principal espacio de socialización (Saraví, 2004, p. 40).

En las últimas décadas se ha discutido ampliamente sobre un supuesto "fin de los espacios públicos", especialmente a partir de trabajos emblemáticos provenientes de Estados Unidos (Mitchell, 1995; Sorkin, 1992), incluyendo la re-afirmación de tal diagnostico después de dos décadas (Mitchell, 2017), teniendo un cierto eco en la bibliografía de América Latina como observa Stillermann (2006). Estos argumentos se basan en una perspectiva crítica, y remiten en parte a una visión algo cultural-pesimista, ligada a una supuesta pérdida de identidad (Sorkin, 1992). Aún, cuando se reconoce que los espacios públicos siempre han contenido componentes de ciudadanía y de comercio a la vez (Mitchell, 1995), el papel constituyente de ciudadanía y de integración son elementos clave para ser "ciudad" $y$, por ende, imprescindibles para un desarrollo urbano sustentable (Németh, 2009). Así, su pérdida destruiría la opción de un desarrollo sustentable. Últimamente se ha enfatizado además el papel de la ciudad compacta, incluyente y con una combinación entre densidad y espacios públicos, abiertos y verdes para la sustentabilidad de espacios urbanos (Pozueta, 2009; Rueda, 2007).

Se ha planteado que en la economía urbana neoliberal se produjo la privatización y mercantilización de los espacios públicos, por la cual ellos adquieren una característica excluyente, segregada, insular y orientada solo al consumo (Carmona, 2014). La valoración económica de los espacios públicos nace a partir de su uso comercial y de las externalidades positivas que generan, siendo entonces un reflejo de la desigualdad y la fragmentación interna de la sociedad urbana (Smith \& Floyd, 2013). En tales condiciones, el espacio público estaría profundizando las diferencias de clase y los 
contrastes entre el consumo privilegiado y los espacios abandonados o descuidados (Loughran, 2014), perdiendo su función de "ágora", incluso llevando a la constatación que "estamos viviendo una agorafobia" (Carrión, 2005, p. 96). En consecuencia, se han masificado los dispositivos de control simbólico o físico, por medio de los cuales, no solamente se afirma la característica comercial de estos espacios, sino además se restringe la libertad cívica (Németh, 2012). Sin embargo, es cuestionable si es que en algún momento el espacio público en general ha presentado realmente dicha cualidad de ser "ágora", o si es más bien la visión modernista la cual ha estado idealizando tal función del espacio público (Mitchell, 1995; Salcedo Hansen, 2002).

En el lenguaje de la máquina de crecimiento, se podría formular que los agentes que conforman la coalición de crecimiento esperan obtener externalidades, por lo cual hasta un cierto grado están dispuestos a invertir para obtener este beneficio. Incluso dentro de una cierta área están dispuestos a compartir esto con otros beneficios. El espacio público entonces se puede interpretar como un bien común, el cual es co-usado simultáneamente sin disminuir el valor de este espacio para el individuo. Los "comunes" se entienden como el derecho de un individuo de no ser excluido de los beneficios y del uso de los recursos presentes en un determinado espacio (Blackmar, 2006).

Tales beneficios de los espacios públicos como bien común se realizan hasta un cierto umbral, a partir del cual se produce "congestión" u otra forma de externalidad negativa (Webster, 2007), por lo cual la visión economicista sobre los espacios públicos está particularmente preocupada por mantener la "calidad" de estos.

"Public space needs to be secured for the turnover of investment. Urban renewal becomes a business strategy which sorts the public as potential consumers according to this strategy. Consumers want to feel safe and comfortable, not forced to face the grim reality of a polarising city" (Bodnar, 2015, p. 7).

Esta cita deja constancia de la expectativa que los espacios públicos tengan un valor para la inversión en las ciudades, particularmente para la inversión inmobiliaria, cuando cumplen con ciertos criterios de "orden". Esto se asocia a la imagen de un espacio vibrante, a los discursos sobre calidad urbana y seguridad, y se relaciona con el concepto de la "máquina de crecimiento" ya que retoma el argumento de una alianza entre la élite económica y política a escala local, para producir crecimiento económico urbano y atraer el capital considerado implícitamente efímero. En esta lógica, la ciudad se entiende como producto de la inversión, agregando valor al inmueble a través de la imagen de la ciudad.

La otra cara del mismo argumento es la lectura que se le da al "desorden" en el espacio público, ya que, por ejemplo, las medidas de vigilancia y control estatal en las ciudades se pueden interpretar suponiendo que la finalidad económica de la imposición de un "orden" en el espacio público, es generar una imagen positiva de la ciudad y así hacerla más atractiva para el capital. Esto es considerado como una característica de la ciudad "revanchista" planteada por Neil Smith (Atkinson, 2003, p. 1833). Sin embargo, hay que considerar que mayor control y medidas visibles de seguridad también pueden provocar la sensación de un espacio peligroso (Stevens, 2009).

\section{Metodología}

El presente estudio tiene característica exploratoria, por 7 lo cual no busca rechazar alguna hipótesis o llegar a resultados con validez general, sino que, pretende identificar a partir de un caso la relevancia de ciertos argumentos teóricos. Con esta finalidad se emplea una aproximación mixta, presentando en una primera parte un análisis de datos cuantitativos, para luego reflexionar sobre elementos del discurso público. Así, se ilustran interpretaciones basadas en la discusión teórica planteada, principalmente en aquellos referidos a la máquina de crecimiento.

Para esta discusión se eligió a la ciudad de Copiapó como caso de estudio, ejemplo para ciudades mineras del norte chileno, por dos principales razones.

1) Ciclo auge-crisis: Copiapó es la capital de una región marcada por el auge en la exportación minera del cobre (Rehner, Rodríguez \& Murray, 2018), sector que a nivel regional aportó el 43\% del PIB de Atacama entre 20062015 (Banco Central de Chile, 2016). Tal dinámica ha transformado la ciudad, en términos demográficos, aumentando en casi 36.000 habitantes en el mismo período (Instituto Nacional de Estadísticas, INE, 2017); en términos laborales el auge ha impulsado el empleo en la 
construcción, pasando de 10.107 a 11.448 trabajadores (2006-2015; SII, 2016), aportando casi el 18\% del PIB de Atacama (entre 2006-2015; Banco Central de Chile, 2016). Así, Copiapó es un ejemplo de ciudad marcada por la actividad minera, con un fuerte aumento de liquidez $y$ disposición a invertir dicho capital en inmuebles. Por otro lado, las caídas de precio del cobre y la cancelación de proyectos, ha impactado fuertemente en la ciudad, por ejemplo, elevando el desempleo en poco tiempo de $3 \%$ hacia más que 9\% (desde agosto 2015 hasta abril 2016; INE, 2017).

2) Inversión: La volatilidad y susceptibilidad a fases de auge y crisis, se ve reflejada también en la inversión recibida. La inversión minera en la cercanía de Copiapó ha marcado el dinamismo de la ciudad durante la última década y ha desencadenado otras inversiones en la ciudad. La inversión en el sector minero mostró un auge a mediados de la primera década del presente siglo, con un fuerte impulso de la inversión extranjera asociada a ellos. Sin embargo, dicha situación comenzó a cambiar cuando dos proyectos mineros ubicados en la cercanía de Copiapó fueron paralizados (2012-2013): Cerro Casale e Inca de Oro, aunque después, Atacama nuevamente se presentó como importante región receptora de inversión extranjera minera (Minería Chilena, 2016). Por otro lado, Copiapó es una de las ciudades con un rápido aumento de la construcción, tendencia que también ha sido afectada por los momentos de crisis (Cámara Chilena de la Construcción, 2013).

La primera parte del trabajo emplea los permisos de edificación otorgados entre 2006 y 2014. La selección de este período se justifica porque permite contrastar tres periodos coyunturales distintos: una primera fase de auge que duró hasta 2008, una segunda fase de crisis en el año 2009 y, por último, una tercera fase que incluye una rápida recuperación post-crisis y un descenso lento pero sostenido entre 2010 y 2014. Los permisos de edificación se obtuvieron de la Dirección de Obras Municipales de Copiapó, los cuales se digitalizaron y georreferenciaron, incluyendo como atributos el destino de las obras (vivienda, comercio, oficinas, entre otros), tipo de permiso (ampliación, obra nueva, modificación, regulación), propietario (persona natural y empresas), como también la superficie edificada y la inversión o los derechos municipales a pagar.

Trabajar con los permisos de edificación presenta como limitante principal que, aquellas obras con permiso otorgado no necesariamente se realizaron, por lo cual en estricto rigor no representa la inversión, sino que, la disposición a invertir en la ciudad (Rehner \& Rodríguez, 2017b). Sin embargo, tal disposición a invertir es para efecto de este trabajo un indicador razonable y el volumen es finalmente un indicador categorial representando de manera suficientemente buena la importancia de la obra respectiva. La base de datos creada permite caracterizar el tipo de propietario, donde se diferenció entre persona natural y empresas, siendo este último actor la agrupación de inmobiliarias, sociedades, constructoras e instituciones. A partir de esto, se obtuvo un panorama general de la dinámica inmobiliaria en la ciudad de Copiapó, contrastando agentes económicos, su expresión en el espacio y en el tiempo. De manera cartográfica se presenta la coincidencia espacial entre la dinámica inmobiliaria y la construcción de espacio público, particularmente en el proyecto Parque Kaukari, complementado por obras de infraestructura de carácter público y, por último, centros comerciales.

En la segunda parte de este trabajo, se propone un análisis exploratorio de discursos asociados a este espacio público, los aspectos valóricos, las proyecciones de la ciudad y las interpretaciones que se asocian con él. Para esto, se recurrió a información pública, proveniente de diversas fuentes como periódicos, reportes del estado del parque y documentos de instituciones gubernamentales como planes oficiales a escala local y regional (Cuadro 1). La inclusión de la cobertura mediática es esencial en el sentido del argumento de la máquina de crecimiento. Por esto se seleccionaron artículos periodísticos publicados principalmente en diarios locales o regionales, con referencia a la construcción del Parque Kaukari, identificados a través de búsqueda en línea. Estos discursos contienen citas de actores vinculados con este proyecto, tales como agentes del sector público en sus diferentes escalas e instituciones asociadas a la construcción y la minería. 
Tabla 1

Fuentes de información revisadas según escala geográfica y ámbito

\begin{tabular}{ll}
\hline Escala & Fuente \\
\hline Nacional & $\begin{array}{l}\text { Gobierno de Chile, revisión de documentos en línea y páginas de internet del Ministerio de Vivienda y Urbanismo y del Ministerio de } \\
\text { Obras Públicas; Cámara Chilena de la Construcción }\end{array}$ \\
\hline Regional & Estrategia Regional de Desarrollo ERD Atacama 2007-2017 \\
\hline Comunal & Plan de Desarrollo Comunal de Copiapó PLADECO 2011-2014; \\
\hline Otro & Medios de comunicación: El Diario de Atacama; Documentos del ámbito académico, específicamente del Centro de Desarrollo \\
\hline
\end{tabular}

Fuente: Elaboración propia.

\section{Permisos de edificación: Temporalidad, distribución espacial y agentes económicos}

En cuanto al número de permisos de edificación otorgados en Copiapó, se muestra una clara predominancia de agentes de carácter particular en el período 2006-2014. Cerca del 78\% de los permisos pertenecen a particulares o de personas naturales, mientras que solo el $9 \%$ corresponden a empresas (Figura 2). Esto contrasta con lo visto en el presupuesto, donde el $87 \%$ de la inversión de los permisos otorgados en el período analizado corresponde al agente empresas, mientras que el resto corresponde a persona natural (Figura 2).

Sin embargo, en cuanto a la espacialidad y temporalidad, se observa que en el periodo 2005 y 2008 la mayor parte de los permisos otorgados a empresas se localizó en la parte norte del río Copiapó, preferentemente cercano al centro de la ciudad o en el principal eje estructurante de la ciudad: Avenida Copayapu y Av. Bernardo O’Higgins (Figura 3). Por otro lado, la localización de los permisos otorgados a personas naturales corresponde principalmente a los sectores de ingreso bajo y medio bajo en el norte y el sur de la ciudad (el sector al norte de Avenida Los Loros y el sector El
Palomar). Esto se vuelve más cercano al argumento de la máquina de crecimiento, al considerar el carácter espacial, donde claramente son las empresas las que invierten en la cercanía del Parque Kaukari, además de obras de infraestructura vial y centros comerciales. En contraposición, la mayoría de los permisos de edificación de particulares se localiza en las periferias norte y sur de Copiapó, algo más alejado de la zona central y el parque en construcción. Esta tendencia va en contra de lo que generalmente se concibe de Copiapó, como una ciudad con poca segregación socio-espacial (Centro de Desarrollo Urbano Sustentable, 2014), ya que significaría mayores beneficios directos y externalidades positivas para los agentes inmobiliarios que para los hogares.

Dicha tendencia se explica por las zonas de urbanización o zonas de expansión urbanizables establecidas en el Plan Regulador Comunal de Copiapó del año 2002, y por las diferentes modificaciones de los años posteriores, donde se establece que, aquellas zonas que concentran la mayor cantidad de permisos de edificación otorgados en el período analizado (Figuras 3 y 4), corresponden a zonas de urbanización destinadas para la vivienda, específicamente zonas con categoría Z-B y Z-C (Biblioteca del Congreso Nacional, 2012). 


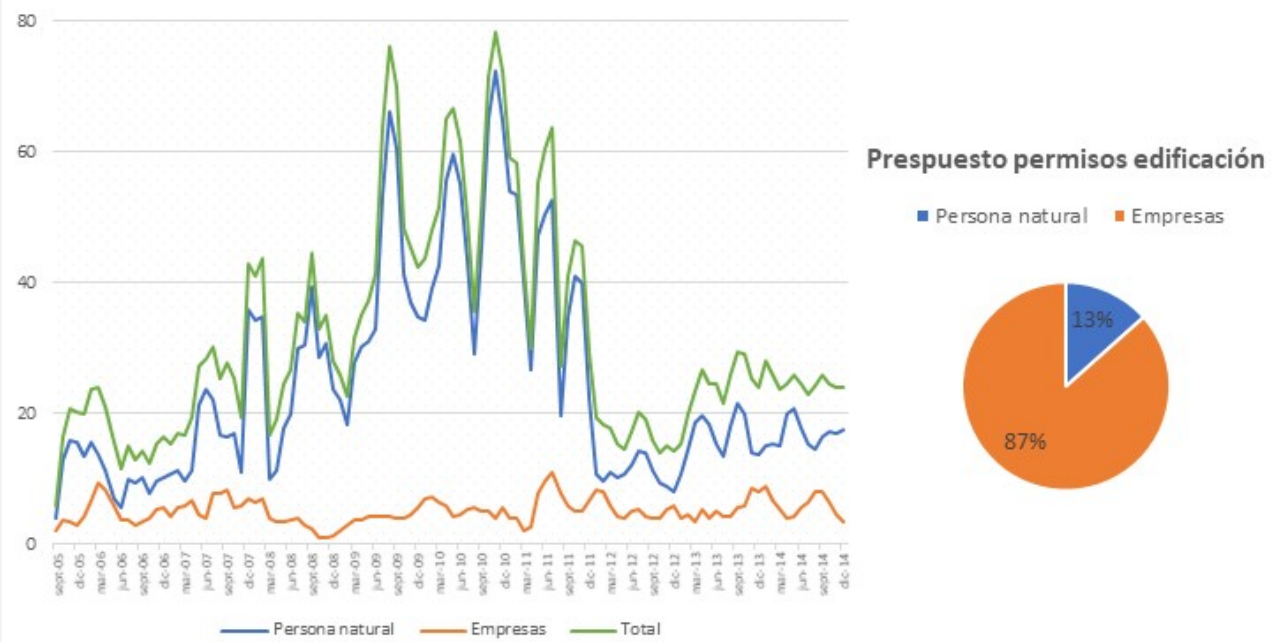

Figura 2: Temporalidad del número de permisos de edificación otorgados en Copiapó (por mes) Fuente: Elaboración propia con base en Dirección de Obras Municipales, DOM Copiapó, 2016.

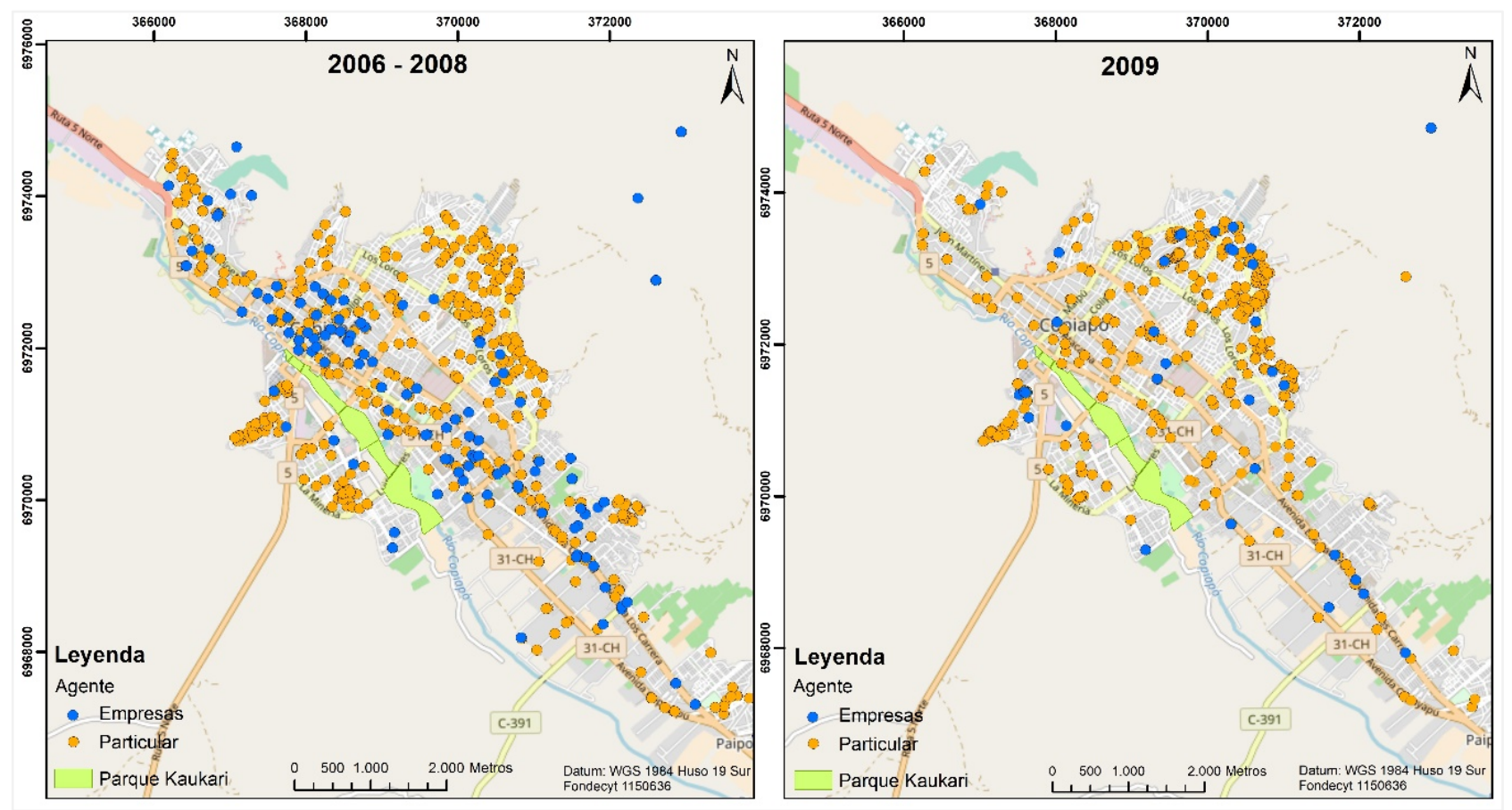

Figura 3: Localización permisos de edificación otorgados en Copiapó. Fuente: Elaboración propia con base en DOM Copiapó, 2016. 

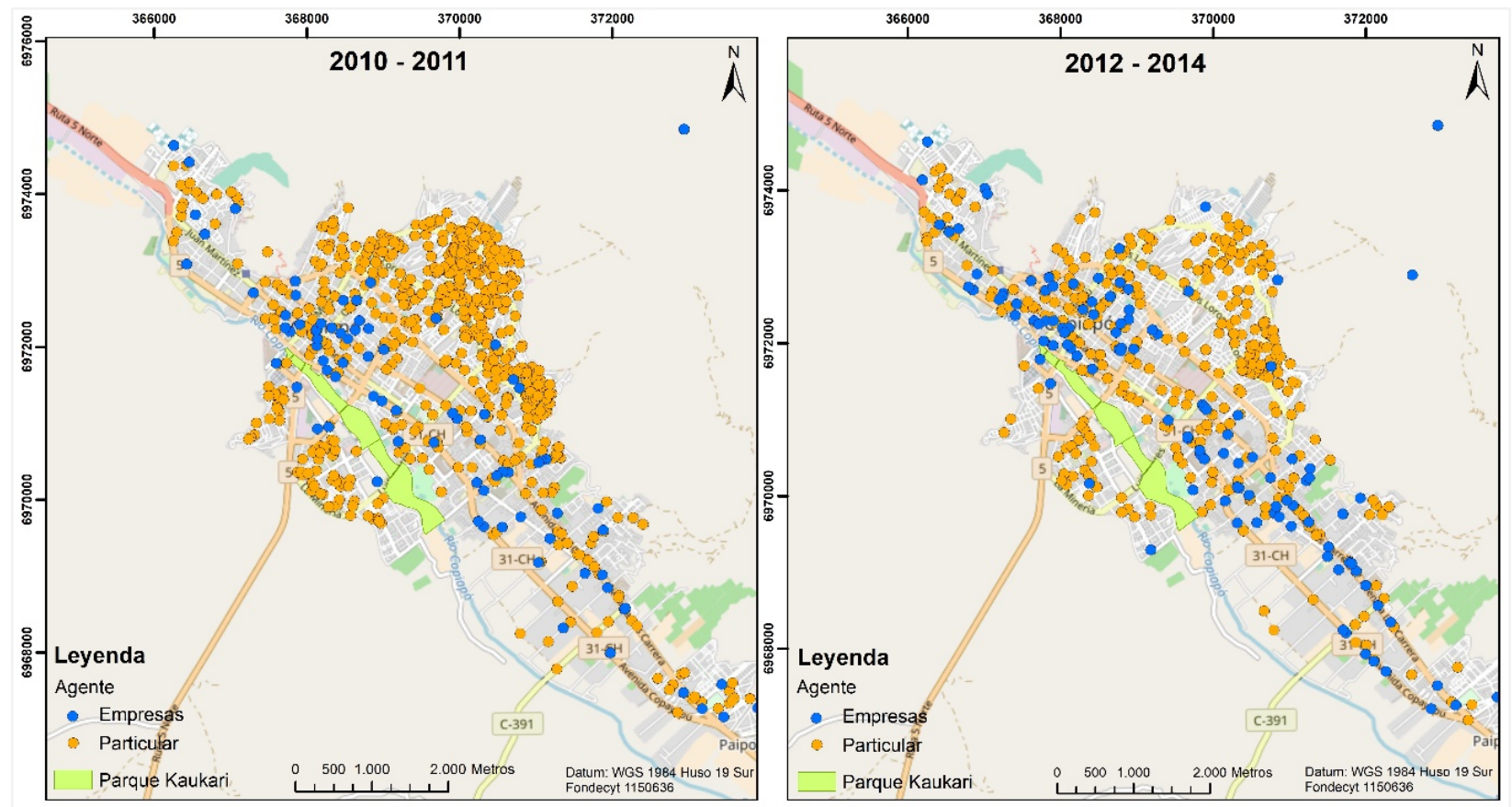

Figura 4: Localización permisos de edificación otorgados en Copiapó Fuente: Elaboración propia con base en DOM Copiapó, 2016.

Durante el año 2009, particularmente marcado por la crisis subprime, se podría haber esperado una disminución en la dinámica inmobiliaria de la ciudad. Sin embargo, se pudo observar que el número de permisos otorgados aumentó considerablemente en este período. Pero esta dinámica en un contexto de crisis global es impulsada casi en su totalidad por agentes particulares, mientras que los permisos otorgados a las empresas (como por ejemplo inmobiliarias) muestran la esperada reducción drástica durante este año de crisis (Figura 2). Es importante considerar que los permisos de personas naturales incluyen ampliaciones de vivienda existente $y$, por ende, son distintos a la inversión inmobiliaria en el estricto sentido de la palabra. Sin embargo, es relevante considerarlos en este análisis ya que son reflejo de una cierta liquidez $y$, sobre todo, expectativa de mejora $y$ crecimiento a escala hogar. Por esto, es relevante observar que su tendencia positiva en el tiempo de crisis contrasta con la sensible reacción del sector inmobiliario a la crisis (Figura 3).

Particularmente en los últimos meses del año 2009 se evidencia además un cambio en el patrón de distribuciónespacial de los permisos de edificación: Aparece una fuerte tendencia de localización en la parte norte de la ciudad, caracterizada principalmente por la presencia mayoritaria de viviendas y configuradas en su mayoría por ampliaciones y regulaciones a estas obras (Figura 3). A partir del año 2010 y durante gran parte del año 2011, tiene lugar un repunte significativo en el número de los permisos, destacando dos pautas espaciales: Por un lado, los permisos de carácter particular se distribuyen de manera relativamente dispersa en gran parte de la zona norte de la ciudad, predominando en este sector vivienda unifamiliar de menor y mediano precio. Por otro lado, los permisos de empresas vuelven a tener un rol protagónico, localizándose preferentemente en el borde norte del río Copiapó a lo largo de los principales ejes de transporte de la ciudad. Finalmente, en el período 2012-2014, se observa una disminución considerable de los permisos de edificación de carácter particular en la zona norte de la ciudad, situación que había caracterizado el período anterior y también, la presencia importante del agente empresas (Figura 4). 
En consecuencia, este análisis demuestra una relación temporal entre la coyuntura global, respectivamente los ciclos de la exportación de cobre con la actividad inmobiliaria, y en términos espaciales se evidencia la orientación de los proyectos presentados por agentes empresariales hacia los principales ejes de transporte y hacia la zona más céntrica. Si bien esto se puede explicar por la característica de uso y precio de suelo, suponiendo que en estas zonas los precios son elevados y por ende menos asequibles para los particulares, también se refleja en esta pauta la tendencia hacia la construcción de un centro de la ciudad inspirado por la morfología de lo que son las grandes urbes con edificios en altura, con edificios corporativos, shopping malls, entre otros. Estos tienden a aglomerarse, y lo hacen en torno a ciertos espacios públicos.

En cuanto a la interpretación del posible valor del proyecto Kaukari relacionado con la espacialidad de los permisos, se debe destacar que si logra las características esperadas alcanzaría por lo menos, en términos de la función (1) de los espacios públicos para la población del sector céntrico, al sur de la Avenida Los Carrera y la Avenida Copayapu, una mejora considerable ya que permitiría una articulación con la ciudad de este sector creciente.
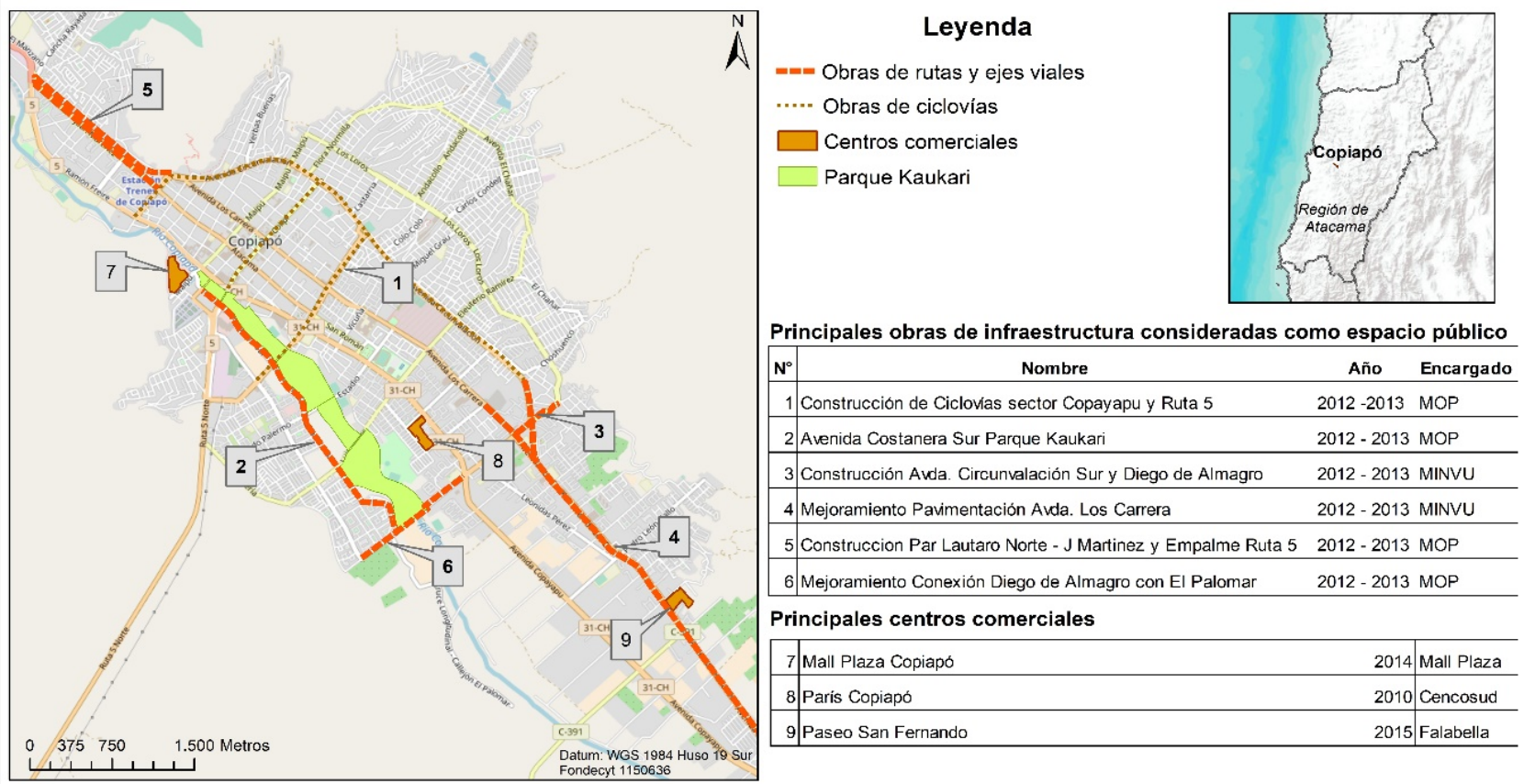

Figura 5: Obras de infraestructura pública y centros comerciales en Copiapó.

Fuente: Elaboración propia con base en Gobierno de Chile, 2011.

pacio público

\begin{tabular}{|c|c|c|c|}
\hline $\mathbf{N}^{\circ}$ & Nombre & Año & Encargado \\
\hline 1 & Construcción de Ciclovias sector Copayapu y Ruta 5 & $2012-2013$ & MOP \\
\hline 2 & Avenida Costanera Sur Parque Kaukari & $2012-2013$ & MOP \\
\hline 3 & Construcción Avda. Circunvalación Sur y Diego de Almagro & $2012-2013$ & MINVU \\
\hline 4 & Mejoramiento Pavimentación Avda. Los Carrera & $2012-2013$ & MINVU \\
\hline 5 & Construccion Par Lautaro Norte - J Martinez y Empalme Ruta 5 & $2012-2013$ & MOP \\
\hline 6 & Mejoramiento Conexión Diego de Almagro con EI Palomar & $2012-2013$ & MOP \\
\hline \multicolumn{4}{|c|}{ Principales centros comerciales } \\
\hline 7 & Mall Plaza Copiapó & 2014 & Mall Plaza \\
\hline 8 & Paris Copiapó & 2010 & Cencosud \\
\hline 9 & Paseo San Fernando & 2015 & Falabella \\
\hline
\end{tabular}

\section{Actividad inmobiliaria y su vínculo con la construcción de espacio público}

El desarrollo urbano de Copiapó de los últimos años ha sido marcado por una serie de obras de infraestructura, con características de espacio público, tales como vías, ejes y rutas de transporte, que permiten la circulación y conexión al interior de la ciudad. La Figura 5 da cuenta de la distribución de los principales proyectos de este tipo de espacio, destacando que dichas obras de infraestructura pública, financiadas por el Estado a través del Ministerio de Obras Públicas y el Ministerio de Vivienda y Urbanismo, se localizan en el centro de la ciudad y los centros comerciales próximos a los principales ejes viales que configuran el tramado urbano. Adicionalmente, la construcción de centros comerciales, por parte de agentes privados (espacios pseudopúblicos), complementan dicha construcción de espacio público. En su conjunto, las obras han contribuido a una consolidación de la centralidad de una franja en el borde sur del centro histórico prolongado hacia el este y oeste. Tanto la infraestructura pública como los centros comerciales tienen un correlato espacial con los permisos de edificación otorgados a los diferentes agentes empresariales $y$, por ende, pueden ser entendidos como expresión espacial de la máquina de crecimiento, más allá de la necesidad objetiva de esta infraestructura. 
Un ejemplo de un espacio público emblemático corresponde al Parque Kaukari, siendo esto un proyecto de gran envergadura y de característica abierta y evidentemente pública. La ciudad enfrenta dos presiones destacadas con relación a este proyecto: Por un lado, sufre de una marcada crisis hídrica, donde hace varios años la cuenca del río Copiapó se encuentra con un déficit permanente (Bitran, Rivera \& Villena, 2014), manifiesto en un lecho del río totalmente seco por varios años (figura 6). Por otro lado, la ciudad de Copiapó presenta un déficit de superficie de áreas verdes, con tan solo 35 ha de áreas verdes (parques y plazas), muy por debajo de las 125 ha o de las 85,7 ha que debería tener Copiapó aplicando las recomendaciones de la OMS o el estándar nacional (Programa de Naciones Unidas para el Medio Ambiente,
PNUMA, 2007). La situación dramática del rio, además de la crisis ambiental, implica la existencia de un extenso espacio deteriorado ubicado en el lecho del río y en sus riberas, atravesando toda la ciudad. Esta situación afecta el desarrollo urbano, dado que este espacio divide la ciudad de forma impactante, no solo en términos visuales, sino también en el sentido de uso de espacio, porque representa una barrera para el tránsito peatonal en la ciudad. Se suma el significado simbólico, ya que desconecta un sector de ingreso medio-bajo del resto de la ciudad. Los recientes eventos de lluvia y las crecidas del río y los aluviones y daños resultantes (2015 y 2017; Valdés-Pineda, Valdés y García-Chevesich, 2017) no cambian la situación de crisis estructural, sino que demuestran aún más claramente la necesidad de acción.

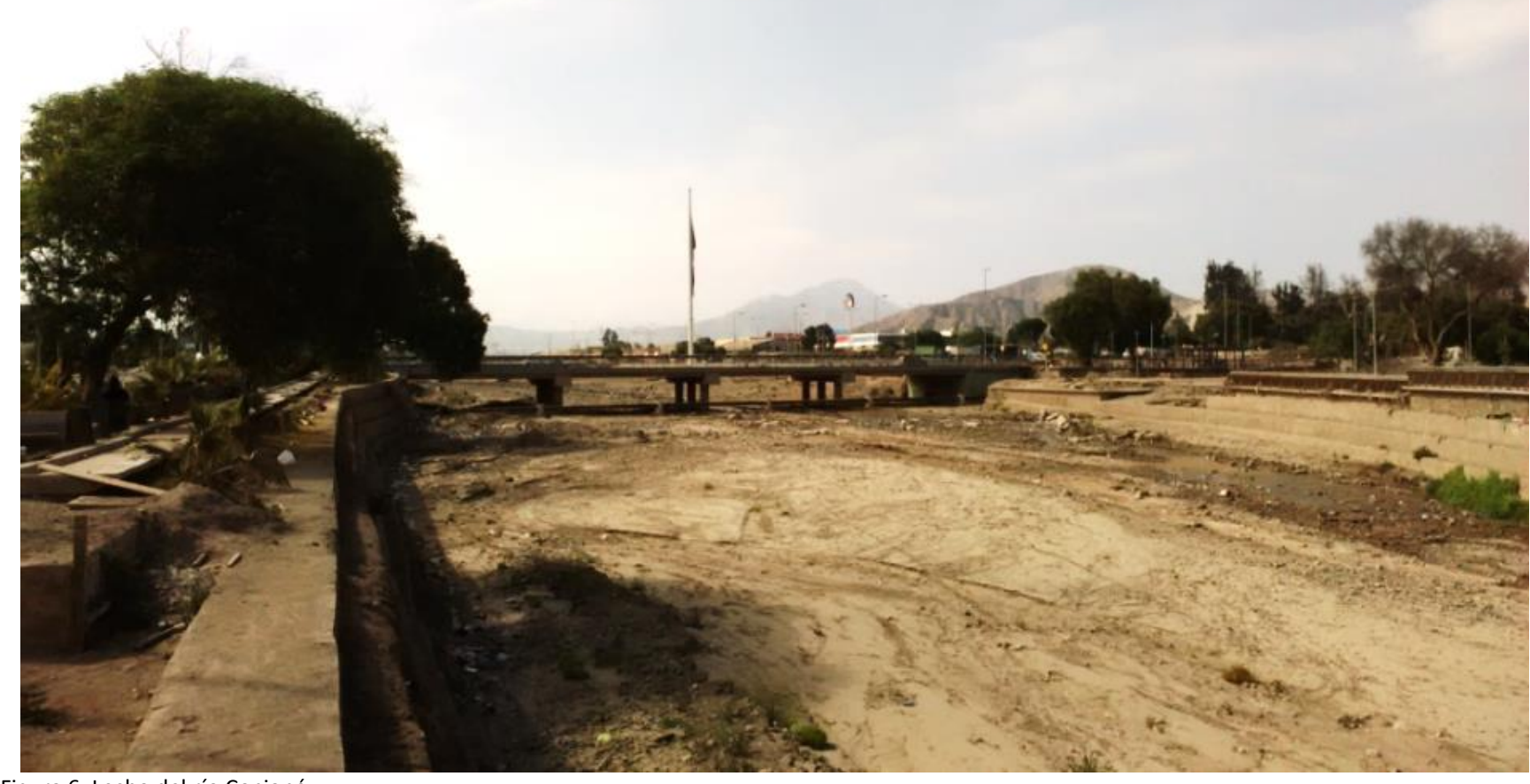

Figura 6: Lecho del río Copiapó.

Fuente: Elaboración propia.

Como respuesta a situación se planteó en 2010 la construcción de un parque público de 58 ha de extensión, con un costo de aproximadamente 30.000 millones de pesos, el cual es financiado por el sector público a escala local y nacional principalmente con fondos del Ministerio de Vivienda y Urbanismo. Se espera que el proyecto Parque Kaukari tenga un fuerte impacto en el desarrollo urbano, específicamente de sus inmediaciones
(Plataforma Arquitectura, 2015). Por esto, suponemos un rol protagónico de los agentes empresariales en la actividad inmobiliaria próxima al área del Parque Kaukari, no tanto en cantidad, sino que en términos de su magnitud. La figura 7 muestra cómo grandes proyectos de agentes empresariales tienden a localizarse en las cercanías del parque, caracterizados por su envergadura, en términos de la superficie y la inversión que se propone. 


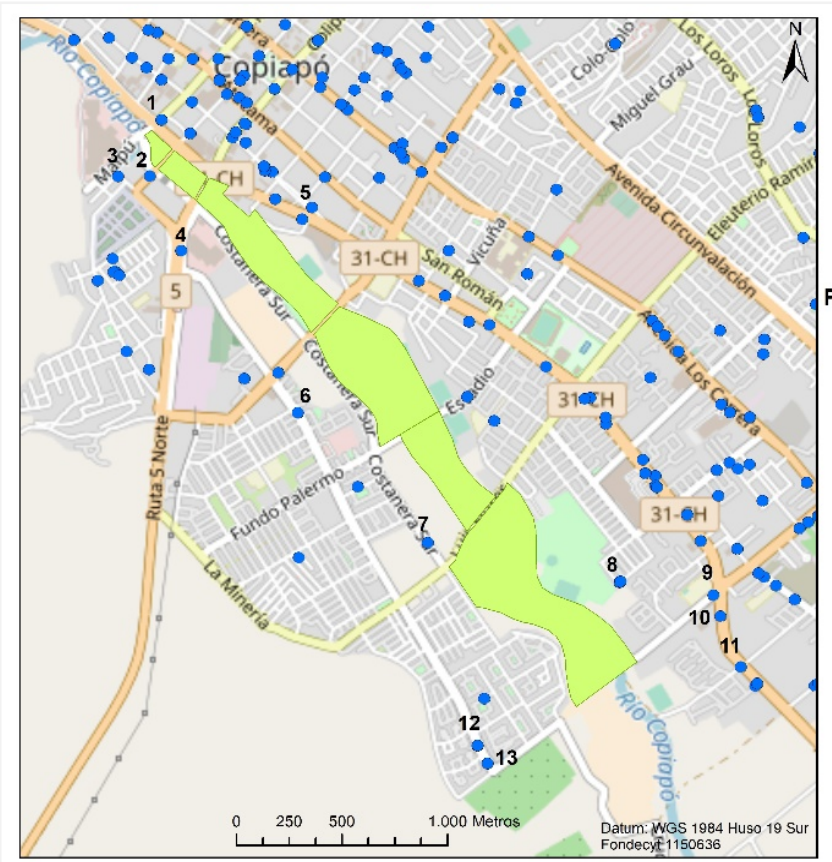

Figura 7: Principales proyectos del agente empresas en Copiapó Fuente: Elaboración propia en base a DOM Copiapó, 2016.

Respecto a las características y funciones del espacio público y en particular, del proyecto Parque Kaukari, se puede observar que este se caracteriza por una funcionalidad y morfología que tendría gran impacto en la ciudad de Copiapó, respondiendo a la necesidad de integrar zonas que se encuentran separadas por el lecho del río, permitir el tránsito de personas, el encuentro y la opinión pública, además de una serie de actividades que se desarrollan en la ciudad. Asimismo, considerando que este espacio se presenta como una intervención urbana

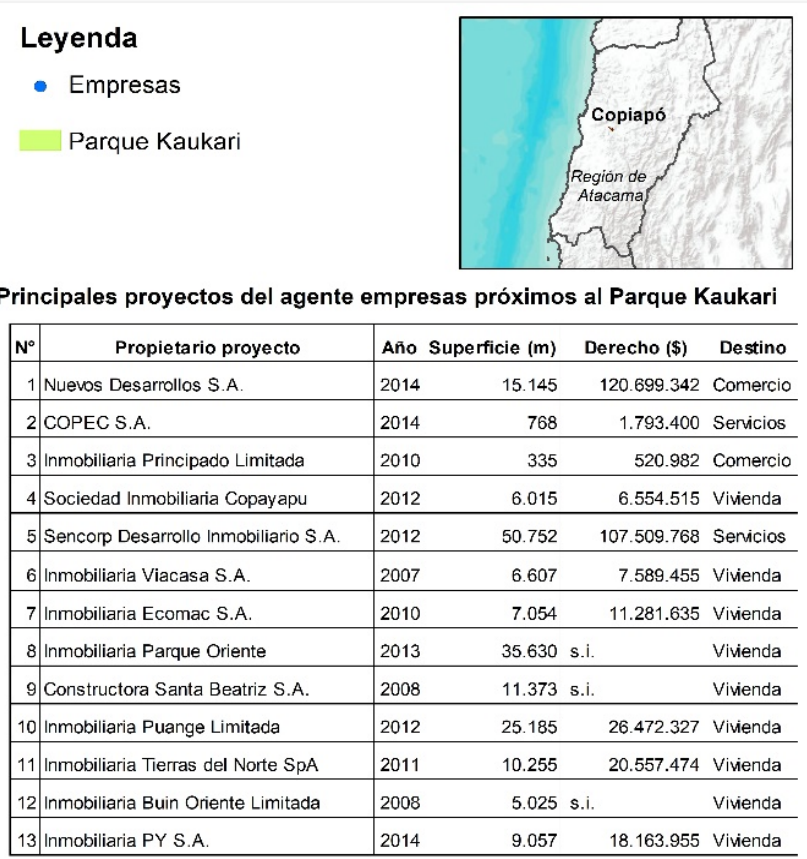

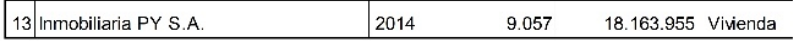



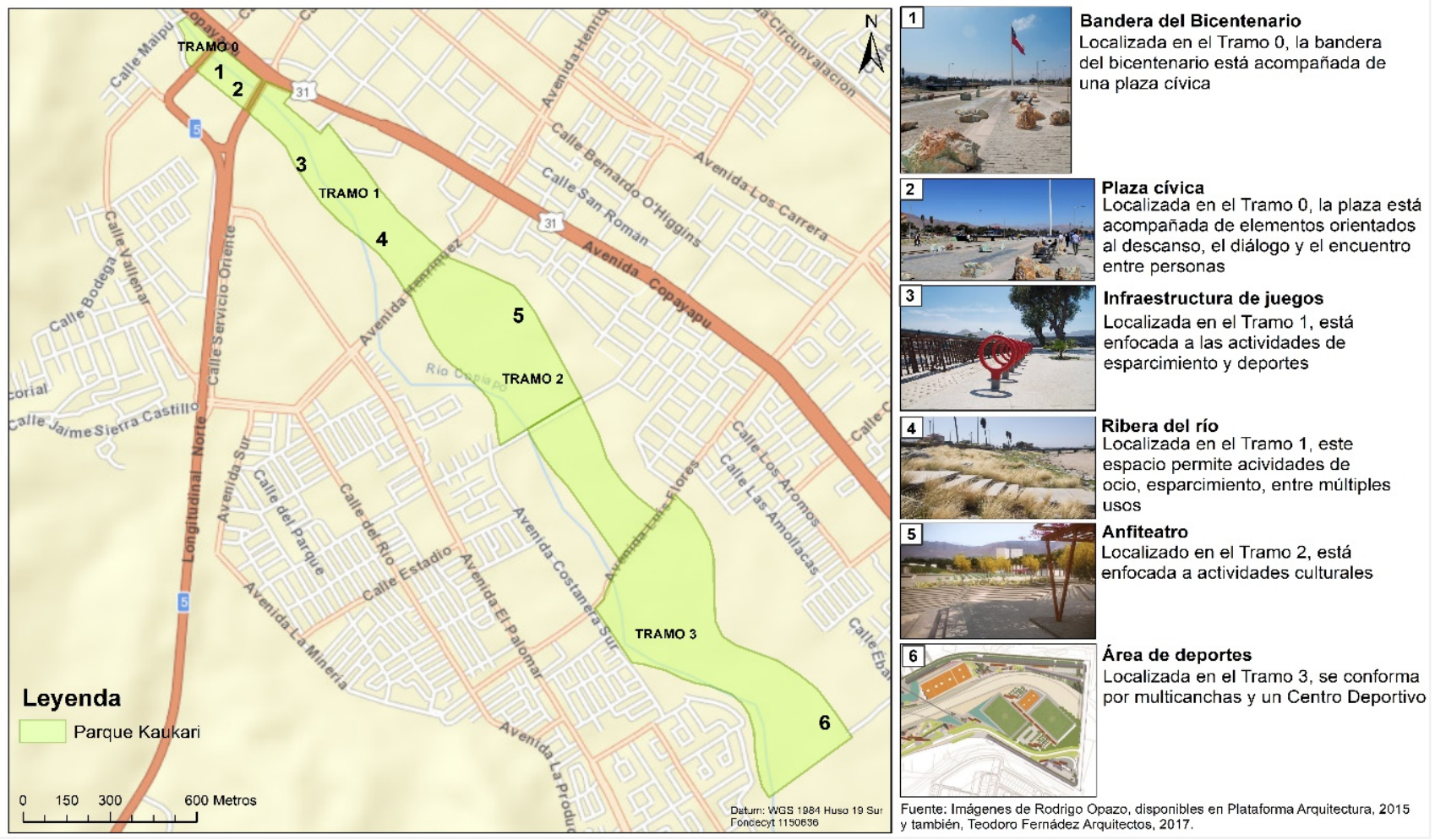

Figura 8: Principales características morfológicas y funcionales del Parque Kaukari

Fuente: Elaboración propia en base a Rodrigo Opazo y Teodoro Fernández Arquitectos (Plataforma Arquitectura, 2015).

\section{El papel del proyecto "Parque Kaukari" en una lectura de la ciudad como máquina de crecimiento}

Evidentemente el proyecto "Parque Kaukari" responde a presiones presentes en la ciudad y los discursos sobre él destacan el valor urbanístico (Diseño Arquitectura, 2018) y políticos como la ex-ministra Paulina Saball enfatizan en su papel integrador (tierraamarrillano, 2018). Pero el análisis anterior sobre el vínculo entre el sector inmobiliaria y la construcción de espacio público en Copiapó, puede ser interpretado bajo la lógica de la “máquina de crecimiento" propuesta por Molotch (1976) y Logan y Molotch (1987). Si bien, la construcción de espacios públicos en la ciudad de Copiapó es financiado principalmente por instituciones estatales a escala nacional a través del Ministerio de Obras Públicas y el Ministerio de Vivienda y Urbanismo, estas decisiones no deberían ser consideradas de forma aislada o netamente técnica, sino que se observa por lo menos en la configuración espacial una articulación con el sector inmobiliario. Esto es sostenido por un discurso sobre la necesidad de crecimiento económico para mayor prosperidad, siendo incluso la construcción del parque mismo presentado como impulso para el dinamismo económico de la ciudad (El Diario de Atacama, 2017). En el sentido de la máquina de crecimiento se debería suponer, que los agentes empresariales buscan prevalecer sus intereses y obtener rentabilidad de estos proyectos urbanos emblemáticos como lo es el Parque Kaukari. Bajo la misma suposición ellos actuarían como coaliciones y alianzas con intereses en común, que pretenden promover el crecimiento urbano de la ciudad.

Lo anterior queda en evidencia en lo que se planteó inicialmente sobre la construcción del Parque Kaukari, esperando que este tenga un fuerte impacto en el desarrollo urbano de sus inmediaciones. En los imágenes y mapas sobre el diseño del Parque aparecen representadas edificaciones de mayor altura y densidad como elementos de un discurso espacial (Diseño Arquitectura, 2018), y estos son formalizados en el Plan Regulador Comunal, lo que crearía valor inmobiliario como externalidad positiva de este proyecto. En particular, el entonces Secretario Regional del Ministerio de Vivienda y Urbanismo, Pablo Carrasco Milla, planteaba que la intención no solo es aumentar las áreas verdes de 
uso público, sino que recuperar 160 hectáreas de zonificación de suelo para la inversión inmobiliaria y mejorar la conectividad vial, convirtiendo al río Copiapó en un espacio público de encuentro, integración social y espacial de una ciudad que hasta ahora está dividida en dos (Ministerio de Vivienda y Urbanismo, 2010). En la cobertura mediática actual se refleja tal expectativa de una mayor plusvalía para los inmuebles vecinos al parque, aunque la dimensión de estos es considerada dudosa (EI Diario de Atacama, 2018).

El surgimiento de esta propuesta de un parque urbano se enmarca en un contexto de auge urbano con proyecciones optimistas hacia una futura importancia destacada de Copiapó no solo nacional, sino que también a nivel internacional. Los discursos sobre su importancia vinculan aspectos representativos y estéticos con lo económico, formulando como objetivo del Parque "revitalizar la imagen de la ciudad" (Ministerio de Vivienda y Urbanismo, 2010). Pablo Carrasco Milla, planteaba que el Parque Kaukari puede llegar a transformarse en el cordón recreacional y la cara visible de un Copiapó que puede salir al mundo con un nuevo producto de exportación (Ministerio de Vivienda y Urbanismo, 2010). En tales visiones de Copiapó, también proyectos privados, como el congelado Atacama Center, el cancelado proyecto del grupo Titanium y el Parque Kaukari jugaron un papel protagónico. El entonces Ministro de Vivienda y Urbanismo, Rodrigo Pérez Mackenna, deja evidencia de este valor simbólico y representativo, argumentando que el Parque Kaukari "debe ser uno de los proyectos de regeneración urbana tal vez más importantes de Chile" (Ministerio de Vivienda y Urbanismo, 2010). Además, este parque fue diseñado por un estudio de arquitectos de destacada reputación en Chile, el cual también diseñó el Parque Bicentenario en la comuna de Vitacura (Diseño Arquitectura, 2018) lo que otorga adicional credibilidad y legitimación al proyecto. Esto, se puede leer como parte de la aspiración de un posicionamiento de la ciudad en el contexto internacional a través del reconocimiento por proyectos emblemáticos.

En tales elementos discursivos se evidencia un estrecho vínculo entre la creación de espacio público, la visión de una ciudad próspera y la inversión inmobiliaria. Dicho argumento queda en evidencia en la postura adoptada por el gremio del sector inmobiliario y de la construcción, quienes argumentan que la felicidad y promesa de una vida mejor para los habitantes está estrechamente ligado a la lógica de crecimiento. En particular, en la Estrategia Regional de Desarrollo de Atacama se plasma, como uno de sus lineamientos, la incorporación de infraestructura para el desarrollo, la competitividad deseada y el diseño de planes de mejoramiento urbano (SUBDERE, 2012). Asimismo, el entonces Consejero Nacional de la Cámara Chilena de la Construcción, Antonio Pardo, planteaba sobre el Plan Copiapó 2050, que "el propósito de este trabajo es vislumbrar el camino correcto para lograr al largo plazo el desarrollo de todas aquellas disciplinas que permitan el encadenamiento virtuoso de: crecimiento económicodesarrollo sostenible-calidad de vida-felicidad de sus habitantes" (Cámara Chilena de la Construcción, 2014).

Sin embargo, son precisamente los actores particulares o la ciudadanía los que juegan un rol clave en la fase inicial del proyecto Parque Kaukari, ya que se requiere su apoyo para un proyecto de esta dimensión en una ciudad con serios desafíos como la escasez y contaminación de agua y el desempleo, entre otros aspectos. Las presentaciones del proyecto Parque Kaukari suelen hacer referencia a la voluntad ciudadana de enfrentar estos desafíos a través de un espacio público de calidad (Diseño Arquitectura, 2018). Al respecto, se observa que el sector público de la época enfatiza que se ha logrado convencer a los ciudadanos que la necesidad por contar con un espacio de encuentro a escala ciudad se vincula con el fomento a la inversión. En palabras de Pablo Carrasco Milla: "se ha instalado en la ciudadanía la importancia de la recuperación del río como espacio de desarrollo de nuevos proyectos tanto públicos como privados" (Ministerio de Vivienda y Urbanismo, 2010). Esto puede ser asociado a la necesidad de las élites económicas y políticas por obtener el apoyo de la ciudadanía y movilizar estas motivaciones en la promoción del crecimiento urbano, planteando que la creación de proyectos a escala ciudad y en este caso, con características de espacio público, permitiría el realce de la vida de los habitantes, fomentaría el sentimiento de orgullo de ser parte de una ciudad exitosa y crearía valor para la ciudadanía.

De esta forma, se puede interpretar que la coalición de actores denominada máquina de crecimiento urbano, 
intenta vincular el deseo de construcción del parque que tienen los habitantes de Copiapó, los diferentes beneficios sociales que este espacio público tendría para ellos y los objetivos de crecimiento que los actores que conforman dicha coalición poseen, a través de lo que Wolfe (1981) plantea como el orgullo cívico de los habitantes. Tal sentimiento de orgullo puede ser una reducción de lo cívico a símbolos nacionales, en un discurso asociado a la unidad nacional y no al encuentro y debate político. El ex presidente Sebastián Piñera banalizó lo cívico, igualándolo con el orgullo nacional expresado en una bandera, señalando que el parque "tendrá un significado muy especial, porque en él se instalará la Bandera Bicentenario, convirtiéndola en una gran plaza cívica, que nos hará recordar lo orgullosos que estamos de ser chilenos" (El Diario de Atacama, 2013, p. 4).

Sin embargo, se señala que el significado de este parque como espacio público, guarda relación con la importancia que este tiene para la ciudadanía, vinculado al concepto de lo "cívico", planteando que "este proyecto es capaz de alojar las diferentes actividades de la ciudadanía, transformándolo en un espacio cívico, cultural, recreativo, paisajístico y deportivo único para Copiapó" (Plataforma Arquitectura, 2015). Además, se argumenta que este espacio permitiría el desarrollo y la expresión de distintas posturas, voluntades y debates políticos. Habría que comprobar en el futuro si efectivamente, una vez finalizada su construcción, se presentará como un espacio de encuentro, de diálogo público para la ciudad. Ya se ha instalado un discurso que, recurriendo a la preocupación ciudadana por el cuidad, reclama por el control de este espacio (El Diario de Atacama, 2018b). Por sobre todo, habría que evaluar en qué medida la expulsión de población que habitaba estos espacios de manera precaria, por ejemplo en la toma Tornini debe ser vista como un elemento de exclusión de grupos específicos, para así obtener una imagen positiva y limpia de la ciudad (El Diario de Atacama, 2011).

Es importante destacar que el proyecto Parque Kaukari se ha mantenido vigente a través de tres cambios de gobierno, superando fases de crisis resultante de precios de cobre en caída y como proyecto de planificación pública ha resistido cuando varios proyectos inmobiliarios fueron cancelados. Resulta llamativo que bajo esta lógica, incluso el gremio del sector inmobiliario reconoce el papel que juega la planificación, citando a su consejero con la afirmación que "la ciudad debe prepararse para capitalizar el crecimiento económico y convertirlo en desarrollo sostenible; esto se logra a través de una adecuada planificación urbana de largo plazo" (Cámara Chilena de la Construcción, 2014).

\section{Conclusiones}

Este trabajo ha tematizado el dinamismo de la construcción en una ciudad minera, mostrando una temporalidad relacionada con los ciclos del cobre y en términos espaciales, se han desarrollado pautas de grandes inversiones públicas y privadas que contribuyen a fortalecer la centralidad en el espacio urbano. Por otro lado, se observa una tendencia de las obras menores, de característica particular, hacia las zonas más periféricas ubicadas en el norte y en el sur de la ciudad. Dentro de estas estructuras destaca el proyecto Parque Kaukari, como espacio público en construcción, el cual en conjunto con las principales vías se convierte en eje articulador y estructurante de esta centralidad reforzada en Copiapó.

El propósito conceptual de este artículo fue evalúa lo pertinente y útil que sería la aplicación del concepto de la "máquina de crecimiento", proveniente del contexto estadounidense para referirse a los procesos de crecimiento urbano de ciudades del norte chileno bajo el ciclo de auge minero y crisis económica. Asimismo, consideramos que este concepto es útil porque permite incorporar 1) la visión de la agencia detrás de grandes proyectos; 2) los elementos discursivos asociados a ello y que se enmarcan en el desarrollo y crecimiento; 3) la legitimación para grandes obras como es el caso del Parque Kaukari y, por último, 4) la coincidencia espacial entre proyectos que generan externalidades positivas y los actores inmobiliarios.

A partir de esto, aparentemente hay una tendencia al desarrollo de proyectos en torno a esta centralidad que se apoya en un discurso de crecimiento económico, progreso y mejora de la imagen de la ciudad, en cual proyectos emblemáticos juegan un papel clave. Esto, se apoya en la cobertura mediática sobre el proyecto Parque Kaukari, la cual transmite mensajes positivos, valorando este espacio como respuesta a algunos desafíos urbanísticos, como por ejemplo el espacio deteriorado en el lecho del rio Copiapó. En este sentido, es que los diferentes discursos públicos identificados hacen referencia, por un lado, a una voluntad manifiesta de los habitantes de la ciudad, 
otorgándole legitimidad local y por sobre todo ciudadana. Por otro lado, los discursos muestran que el parque, como espacio público emblemático, promete contribuir en conjunto con el desarrollo del centro de la ciudad, a la generación de un espacio atractivo para los proyectos inmobiliarios. Esto último adquiere relevancia al considerar que la construcción del proyecto Parque Kaukari muestra una continuidad en el tiempo, a pesar de los tres cambios de gobierno existentes en este período. Finalmente, un punto a destacar es que, en este caso, a diferencia de la propuesta original sobre la máquina de crecimiento, tanto los discursos como los flujos financieros, como los ciclos coyunturales, están arraigados en una escala superior (nacional hasta global), por lo cual se plantea que la discusión teórica tiene que ser ampliada en el sentido de un análisis escalar.

Bajo la mirada del concepto del desarrollo urbano sustentable, el Parque Kaukari permite dos lecturas contrastantes. Por un lado, los diferentes elementos presentados podrían ser considerados como parte del argumento detrás que lo que Molotch propone como la máquina de crecimiento y por ende estaría contrario a un entendimiento más fuerte de la sustentabilidad, ya que prioriza la máxima de crecimiento. Como se pudo ver, en buena parte de los discursos vinculados con la construcción del parque, la búsqueda de crecimiento a

\section{Referencias}

Atienza, M., Lufín, M., Soto, J., y Cortés, Y. (2015). ¿Es la Región de Antofagasta un caso exitoso de desarrollo local basado en la minería? En C. Rodríguez et. al. (Ed.), Sistemas, coaliciones, actores y desarrollo económico territorial en regiones mineras (pp. 97-117). Innovación Territorial Aplicada. Antofagasta: Universidad Católica del Norte.

Atkinson, R. (2003). Domestication by Cappuccino or a revenge on urban space? Control and Empowerment in the Management of Public Spaces. Urban Studies, 40(9), 1829-1843. https://doi.org/10.1080/0042 098032000106627

Auty, R M. (1993). Sustaining development in mineral economies: The resource curse thesis. London: Routledge. partir de la construcción de un espacio público, según tal lectura, estaría asociado a la generación de externalidades positivas que podrían favoreces agentes inmobiliarios, y que estarían asociado a un fuerte crecimiento material de la ciudad, cuestionando la sustentabilidad urbana. Asimismo, la sustentabilidad del parque mismo tendría que ser evaluado en futuros estudios, considerando las propuestas de enfatizar las especies endémicas y el uso de aguas grises para el riego (Soy Chile, 2018).

Por otro lado, la construcción del proyecto Parque Kaukari también puede ser considerada una respuesta a los diferentes desafíos que presenta la ciudad en la actualidad, particularmente aquel referido a la evidente deficiencia de espacios públicos de calidad que sufre Copiapó. Por ende, la promesa del parque de aportar a la integración de distintos espacios urbanos en la ciudad, a generar espacio de inclusión, de encuentro, de diálogo y su evidente contribución de fortalecer la centralidad, genera la esperanza que esto sea un aporte al desarrollo sustentable de Copiapó. Así, incluso la búsqueda de crecimiento planteada en el argumento de Molotch, puede ser un aporte a un desarrollo sustentable, cuando esté enfocada en mejorar la calidad de vida y el bienestar de los habitantes de la ciudad, y en crear una urbe más inclusiva.

Badeeb, R., Lean, H. \& Clark, J. (2016). The evolution of the natural resource curse thesis: A critical literature survey. Working Paper, Department of Economics and Finance College of Business and Law University of Canterbury (5), 1-32. Recuperado de https://idea s.repec.org/p/cbt/econwp/16-05.html

Banco Central de Chile. (2016). Base de datos estadísticos. Cuentas Nacionales. PIB regional por actividad económica. Recuperado de http://si3.bcentral.c I/Siete/secure/cuadros/arboles.aspx

Biblioteca del Congreso Nacional. (2012). Aprueba modificación del Plan Regulador Comunal de Copiapó, Sector Río Copiapó. Recuperado de https://www.ley chile.cl/Navegar?idNorma $=1043657$ 
Bitran, E. Rivera, P., \& Villena, M. (2014). Water management problems in the Copiapó Basin, Chile: Markets, severe scarcity and the regulator. Water Policy, 16(5), 844-863. https://doi.org/10.2166/wp.2 $\underline{014.107}$

Blackmar, E. (2006). Appropiating "the Commons": The tragedy of the property rights discourse. En S. Low \& N. Smith (Eds.), The Politics of Public Space (pp. 49-80). New York \& London: Routledge.

Bodnar, J. (2015). Reclaiming public space. Urban Studies Virtual Special Issue, 52(12), 1-15. https://doi.org/10.1177/0042098015583626

Borja, J. (2007). Revolución y contrarrevolución en la ciudad global: las expectativas frustradas por la globalización de nuestras ciudades. EURE, 33(100), 3550. https://doi.org/10.4067/s0250-716120070003000 $\underline{03}$

Borja, J. y Muxi, Z. (2000). El espacio público, ciudad y ciudadanía. Recuperado de http://www.esdionline.com/repositori/public/dossiers/DIDAC wdw7y dy1.pdf

Cámara Chilena de la Construcción. (2014). Se realizó presentación del estudio "Gran Copiapó 2050". Recuperado de http://www.cchc.cl/comunicaciones Lnoticias/64984-se-realizo-presentacion-del-estudiogran-copiapo-2050

Cámara Chilena de la Construcción. (2013). Atacama construye. Recuperado de http://www.cchc.cl/upload s/archivos/archivos/REVISTA-ATACAMACONSTRUYE.pdf

Carrión, F. (2005). El centro histórico como proyecto y objeto de deseo. EURE, 31(93), 89-100. https://doi.o $\mathrm{rg} / 10.4067 / \mathrm{s} 0250-71612005009300006$

Carmona, M. (2014). Re-theorising contemporary public space: A new narrative and a new normative. Journal of Urbanism: International Research on Placemaking and Urban Sustainability, 8(4), 373-405. https://do i.org/10.1080/17549175.2014.909518

Centro de Desarrollo Urbano Sustentable, Cedeus. (2014). Síntesis principales resultados Conversatorios Urbanos Copiapó. Recuperado de http://www.cedeus.c I/vinculacion-con-el-medio/sintesis-principalesresultados-conversatorios-urbanos-copiapo/
Cook, I. R. \& Whowell, M. ( 2011). Visibility and the policing of public space. Geography Compass, 5(8), 610-622. https://doi.org/10.1111/j.1749-8198.2011. 00437.x

Corden, W. \& Neary, J. (1982). Booming sector and deindustrialization in a small open economy. The Economic Journal, 92(368), 825-848. https://doi.org/ $\underline{10.2307 / 2232670}$

Corden, W. M. (1984). Booming sector and Dutch disease economics: Survey and consolidation. Oxford Economic Papers, 36(3), 359-380. https://doi.org/10. 1093/oxfordjournals.oep.a041643

Daher, A. (2003). Regiones-commodities. Crisis y contagio en Chile. EURE, 29(86), 89-108. https://doi.org/10.40 67/s0250-71612003008600005

Daher, A. (2017). El fin del súper ciclo del cobre en las regiones y comunas mineras en Chile. En C. Rodríguez et al. (Eds.), Las regiones mineras después del auge de los recursos naturales (16-34). Innovación Territorial Aplicada. Antofagasta: Universidad Católica del Norte.

División de Desarrollo Urbano, DDU/Ministerio de Vivienda y Urbanismo de Chile. (2009). Espacios públicos. Recomendaciones para la gestión de proyectos. Santiago de Chile: Ministerio de Vivienda y Urbanismo.

Defilippis, J. (1997). From a public re-creation to private recreation: The transformation of public space in south street seaport. Journal of Urban Affairs, 19(4), 405417. https://doi.org/10.1111/j.1467-9906.1997.tb005 $\underline{04 . x}$

Dirección de Obras Municipales, DOM Copiapó. (2016). Permisos de edificación otorgados por el Municipio de Copiapó, período 2005-2014. Copiapó: Autor.

Diseño Arquitectura. (2018). Parque Kaukari de Teodoro Fernández. Recuperado de http://www.disenoarqu itectura.cl/parque-kaukari-teodoro-fernandez/

El Diario de Atacama. (2011). Mall Plaza presentó anteproyecto para Copiapó. El Diario de Atacama. Recuperado de http://www.diarioatacama.cl/pro ntus4 nots/site/artic/20110602/pags/201106020015 20.html

El Diario de Atacama. (2013). Presidente Sebastián Piñera puso la primera piedra del proyecto Kaukari. El Diario 
de Atacama. Recuperado de www.eldiariodea $\underline{\text { tacama.cl }}$

El Diario de Atacama. (2018). Tasadores comentaron los efectos del Kaukari en las propiedades cercanas. EI Diario de Atacama. Recuperado de www.eldiariodea tacama.cl

El Diario de Atacama. (2018b). El Kaukari maravilla a sus visitantes, aunque preocupa su cuidado. El Diario de Atacama. Recuperado de www.eldiariodeatacama.cl

Gehl, J. (2006). La humanización del espacio urbano. La vida social entre los edificios. Estudios Universitarios de Arquitectura 9. Barcelona: Reverté.

Gobierno de Chile. (2011). Plan regional de Atacama 20102014. Recuperado de http://2010-2014.gob.cl/med ia/2011/01/plan atacama.pdf

Harvey, D. (1978). The urban process under capitalism: A framework for analysis. International Journal of Urban and Regional Research, 2(1-3), 101-131. https://doi.or g/10.1111/j.1468-2427.1978.tb00738.x

Harvey, D. (2006). The political economy of public space. En S. Low \& N. Smith (Eds.), The politics of public space (pp. 17-34). New York \& London: Routledge.

Instituto Nacional de Estadísticas, INE. (2017). Población comunal por sexo y edad. Recuperado de http://www.i ne.cl/estadisticas/demograficas-y-vitales

Irarrázaval, F. (2012). El imaginario "verde" en el verde urbano como instrumento de consume inmobiliario: configurando las condiciones ambientales del área metropolitana de Santiago. Revista INVI, 27(75), 73103. https://doi.org/10.4067/s0718-8358201200020 $\underline{0003}$

Jacobs, J. (1958). Downtown is for people. Fortune Magazine. Recuperado de http://fortune.com/2011 /09/18/downtown-is-for-people-fortune-classic1958/

Jacobs, J. (1961). The death and life of great American cities. New York: Random House.

León Balza, S. F. (1998). Conceptos sobre espacio público, gestión de proyectos y lógica social: reflexiones sobre la experiencia chilena. Revista EURE, 24(71), 27-36. https://doi.org/10.4067/s0250-71611998007100002
Logan, J. \& Molotch, H. (1987). Urban fortunes: The political economy of place. Berkeley, U.S.: University of California Press.

Loughran, K. (2014). Parks for profit: The high line, growth machines, and the uneven development of urban public spaces. City \& Community, 13(1), 49-68. https://doi.org/10.1111/cico.12050

Minería Chilena. (2016). Compendio de la Minería Chilena 2016. Santiago de Chile: Grupo Editec.

Ministerio de Vivienda y Urbanismo. (2010). Parque Urbano Kaukari. Seremi Región de Atacama. Recuperado de http://www.minvuatacama.gob.cl/ opensite det 20101203125650.aspx

Ministerio de Vivienda y Urbanismo. (2017). La dimensión humana en el espacio público. Recomendaciones para el análisis y el diseño. Santiago de Chile: Autor.

Mitchell, D. (1995). The end of public space? People's park, definitions of the public, and democracy. Annals of the Association of American Geographers, 85(1), 108-133. Recuperado de http://sites.middlebury.ed u/igst404/files/2014/01/Mitchell-End-of-PublicSpace.pdf

Mitchell, D. (2003). The right to the city: Social justice and 20 the fight for public space. New York: Guilford Publications.

Mitchell, D. (2017). People's park again: On the end and ends of public space. Environment and Planning $A$ 49(3), 503-518. https://doi.org/10.1177/0308518×15 611557

Molotch, H. (1976). The city as growth machine: Toward a political economy of place. American Journal of Sociology, 82(2), 309-332. https://doi.org/10.1086/ 226311

Muñoz-García, J. (2011). Búsqueda de rentas, recursos naturales y crecimiento económico: Chile, Noruega, Botswana y Zimbabwe. Revista Laissez-Faire, 35, 2634. Recuperado de http://laissezfaire.ufm.edu/index. php?action=ajax\&rs=GDMgetFile\&rsargs[]=Laissezfair e35 2.pdf

Németh, J. (2009). Defining a public: The management of privately owned public space. Urban Studies, 46(11), 2463-2490. https://doi.org/10.1177/0042098009342 $\underline{903}$ 
Németh, J. (2012). Controlling the commons: How public is public space? Urban Affairs Review, 48(6), 811-835. https://doi.org/10.1177/1078087412446445

ONU Habitat y CAF. (2014). Construcción de ciudades más equitativas. Políticas públicas para la inclusión en América Latina. Recuperado de https://unhabitat.org/ books/construccion-de-ciudades-mas-equitativaspoliticas-publicas-para-la-inclusion-en-america-latina/

Pike, A. \& Pollard, J. (2010). Economic geographies of financialization. Economic Geography, 86(1), 29-51. https://doi.org/10.1111/i.1944-8287.2009.01057.x

Plataforma Arquitectura. (2015). Parque urbano Kaukari / Teodoro Fernández Arquitectos. Recuperado de http:// www.plataformaarquitectura.cl/cl/629488/kaukariurban-park-teodoro-fernandez-arquitectos

Pozueta, J. (2009). Evolución de la consideración de los corredores verdes en la planificación: el caso de Madrid. Revista de Urbanismo, 20, 1-36. https://revist aurbanismo.uchile.cl/index.php/RU/article/view/10

Programa de Naciones Unidas para el Medio Ambiente, PNUMA. (2007). Perspectivas del medio ambiente urbano: Geo Copiapó. Recuperado de http://www.pn uma.org/deat1/pdf/2009\%20\%20GEO\%20Copiapo.pdf

Rehner, J. y Vergara, F. (2014). Efectos recientes de la actividad exportadora sobre la reestructuración urbana en Chile. Revista de Geografía Norte Grande, 59, 83-103. https://doi.org/10.4067/s0718-34022014 $\underline{000300006}$

Rehner, J. y Rodríguez-Leiva, S. (2017). Inversión inmobiliaria en tiempos de auge y crisis: ¿Es la ciudad un producto minero o un derivado financiero? Revista de Geografía Norte Grande, 67, 183-201. https://doi. org/10.4067/s0718-34022017000200010

Rehner, J. y Rodríguez, S. (2017b). Dinámicas inmobiliarias en ciudades del norte y sur de país. Anales de Geografía. Recuperado de http://sociedadchilenad ecienciasgeograficas.cl/2014/wpcontent/uploads/2014/10/Anales-2016.pdf

Rehner, J., Baeza, S., \& Barton, J. (2014). Chile's resourcebased export boom and its outcomes: Regional specialization, export stability and economic growth. Geoforum, 56, 35-45. https://doi.org/10.1016/j.ge oforum.2014.06.007
Rehner, J., Rodríguez, S., y Murray, W. (2018). Ciudades en auge en Chile: rol de la actividad exportadora en la dinámica del empleo urbano. EURE, 44(131), 151-171. https://doi.org/10.4067/s0250-71612018000100151

Ríos, D. y Pírez, P. (2008). Urbanizaciones cerradas en áreas inundables del Municipio de Tigre: ¿Producción de espacio urbano de alta calidad ambiental? EURE, 34(101), 99-119. https://doi.org/10.4067/s0250$\underline{71612008000100005}$

Rueda, S. (2007). Un nuevo urbanismo para abordar los retos de la sociedad actual. Neutra: Revista del Colegio Oficial de Arquitectos de Andalucía Occidental, 15, 3037. Recuperado de https://dialnet.unirioja.es /servlet/articulo?codigo $=2355382$

Sachs, J. D. y Warner, A. D. (1995). Natural resource abundance and economic growth. NBER Working Paper, (5398), 1-54. Recuperado de https://econpape rs.repec.org/scripts/redir.pf?u=http\%3A\%2F\%2Fwww .nber.org\%2Fpapers\%2Fw5398.pdf;h=repec:nbr:nber wo:5398

Salcedo Hansen, R. (2002). El espacio público en el debate actual: una reflexión crítica sobre el urbanismo postmoderno. Revista EURE, 28(84), 5-19. https://doi. org/10.4067/s0250-71612002008400001

Sánchez, A., García de la Cruz, J., y Mora, A. (2014). Comercio internacional, materias primas $y$ enfermedad holandesa: estudio comparativo de los efectos estáticos en Noruega y Chile. Revista de Economía Mundial, 39, 179-200. http://www.redalyc. org/articulo.oa?id=86639636007

Saraví, G. (2004). Segregación urbana y espacio público: los jóvenes en enclaves de pobreza estructural. Revista de la CEPAL, 83, 33-48. https://www.insumisos. com/lecturasinsumisas/Segregacion\%20urbana\%20y \%20espacio\%20publico.pdf

Servicio de Impuestos Internos, SII. (2016). Estadísticas de empresas según tamaño por ventas. Recuperado de http://www.sii.cl/estadisticas/empresas tamano ven tas.htm

Servicio Nacional de Aduanas. (2016). Estadísticas de exportaciones. Recuperado de https://www.aduana .cl/exportaciones/aduana/2007-04-16/165951.html

(1)


Smith, J. W. \& Floyd, M.F. (2013). The urban growth machine, central place theory and access to open space. City, Culture and Society, 4(2), 87-98. https://doi.org/10.1016/j.ccs.2013.03.002

Sorkin, M. (Ed.) (1992). Variations on a theme park: The new American city and the end of public Space. New York: Hill and Wang.

Soy Chile (2018). El parque Kaukari será $100 \%$ sustentable con planta de aguas grises. Recuperado de http://www.soychile.cl/

Springer, S. (2011). Public space as emancipation: Meditations on anarchism, radical democracy, neoliberalism and violence. Antipode, 43(2), 525-562. https://doi.org/10.1111/j.1467-8330.2010.00827.x
Stevens, Q. (2009). 'Broken' public spaces in theory and in practice. Town Planning Review, 80(4-5), 371-391. https://doi.org/10.3828/tpr.2009.3

Valdés-Pineda, R., Valdés, J.B., y García-Chevesich, P. (2017). Modelación de crecidas aluvionales en la Cuenca del Río Copiapó, Chile. Ingeniería del Agua, 21(2), 135-152. https://doi.org/10.4995/ia.2017.7366

Van Wijnbergen, S. (1984). The 'Dutch Disease': A disease after all? The Economic Journal, 94(373), 41-55. https://doi.org/10.2307/2232214

Webster, C. (2007). Property rights, public space and urban design. Town Planning Review, 78(1), 81-101. https://doi.org/10.3828/tpr.78.1.6

Wolfe, A. (1981). America's impasse: The rise and fall of the politics of growth. Nueva York: Pantheon Book 